\title{
Maturação e dormência em diásporos de carrapicho-de-carneiro (Acanthospermum hispidum DC. - Asteraceae) ${ }^{1}$
}

\author{
Edson Ferreira Duarte ${ }^{2 *}$, Jaylson Araújo dos Santos², Jailson de Souza Peixoto², \\ Carlos Henrique Barbosa Santos ${ }^{2}$
}

\begin{abstract}
RESUMO - Objetivou-se acompanhar a maturação dos diásporos de carrapicho-de-carneiro (Acanthospermum hispidum DC.) e avaliar métodos de superação da dormência. Diásporos com 7, 14, 21, 28 e 35 dias após antese (DAA) obtidos em plantas ocorrentes na área experimental da Universidade Federal do Recôncavo da Bahia, Cruz das Almas, BA, Brasil. Foram avaliadas as dimensões dos diásporos de cada estádio, seu teor de água e de massa seca. Fez-se um teste de emergência de plântulas, a $25^{\circ} \mathrm{C}$, sob 16 horas de luz em areia lavada. Avaliou-se semanalmente a emissão da parte aérea, determinando o índice de velocidade de emergência (IVE) e a porcentagem de diásporos mortos e dormentes. Em outro experimento, utilizaram-se tratamentos para superação da dormência: escarificação com lixa; lavagem em água corrente por 24 horas; estratificação a $10{ }^{\circ} \mathrm{C}$ por sete dias; $\mathrm{GA}_{3}$ a $4000 \mathrm{mg} \mathrm{L} \mathrm{L}^{-1}$; sementes intactas. Ocorreram incrementos na largura e na massa da matéria seca até 21 DAA, o comprimento aumentou até 35 DAA. A máxima emergência de plântulas $(45 \%)$ e o máximo IVE $(3,4)$ ocorreram aos 21 DAA, quando ocorreu a maturidade fisiológica; nos estádios seguintes verificou-se aumento da dormência. A. hispidum dispersa sementes fisiologicamente dormentes e a dormência é superada com $\mathrm{GA}_{3}$.
\end{abstract}

Termos para indexação: planta daninha, germinação, vigor, giberelina.

\section{Maturation and dormancy in Acanthospermum hispidum DC. - Asteraceae diaspores}

\begin{abstract}
The objective of the study was to evaluate the maturation of A. hispidum diaspores and methods for overcoming dormancy. Diaspores were obtained 7, 14, 21, 28 and 35 days after anthesis (DAA) from plants in the experimental area of the Universidade Federal do Recôncavo Bahiano, Cruz das Almas, Bahia, Brazil. Diaspore dimensions, water content and dry weight were evaluated. Emergence was tested at $25^{\circ} \mathrm{C}$ with 16 hours of light in washed sand. Emergence was monitored weekly, counting the aerial part of the seedlings above the substrate, and determining the germination velocity emergence (GVE) and percentage of dead and dormant diaspores. In another experiment, the treatments for overcoming dormancy were: scarification with sandpaper; washing in running water for $24 \mathrm{~h}$; stratification at $10{ }^{\circ} \mathrm{C}$ for 7 days; $\mathrm{GA}_{3} 4000 \mathrm{mg} \mathrm{L}^{-1}$; and intact seeds. The dry weight increased until 21 days and the length increased until 35 DAA. The maximum emergence $(45 \%)$ and GVE (3.4) of the diaspores was at 21 DAA when there was physiological maturity. Dormancy increased in the subsequent stages. A. hispidum disperses physiologically dormant seeds and dormancy can be overcome with $\mathrm{GA}_{3}$.
\end{abstract}

Index terms: weed, germination, vigor, gibberellin.

\footnotetext{
${ }^{1}$ Submetido em 20/01/2011. Aceito para publicação em 24/02/2012.

${ }^{2}$ Centro de Ciências Agrárias, Ambientais e Biológicas, Universidade Federal do Recôncavo da Bahia (UFRB), 44380-000-Cruz das Almas, BA, Brasil.

*Autor para correspondência <duarteef@ufbr.edu.br>
} 


\section{Introdução}

A determinação da maturidade das sementes pode auxiliar no entendimento da dinâmica do banco de sementes no solo (Martins et al., 2004). Dessa forma, há a necessidade de realização de estudos nas sementes das plantas daninhas, relativos à sua maturação e a dormência, os quais podem apoiar a definição de métodos de manejo e controle.

A dormência em sementes de plantas daninhas pode ser regulada por mecanismos de dormência embrionária (morfológica), tegumentar (física), mecânica, inibidores (química), fisiológica (balanço hormonal) ou pela combinação desses mecanismos, os quais são afetados por fatores externos (temperatura, água e luz) (MarcosFilho, 2005; Vivian et al., 2008; Ross e Lembi, 2009). Esses autores consideram a dormência importante na sobrevivência dessas espécies por meses ou anos no banco de sementes solo.

A impermeabilidade do tegumento das sementes limita a germinação, mas por outro lado, aumenta a longevidade das sementes no solo e a persistência nas áreas de cultivo. O rompimento do tegumento promove a superação desse tipo de dormência, mas pode levar à decomposição dos tecidos da semente pelo ataque por microrganismos (Ross e Lembi, 2009).

A germinação também pode ser limitada por inibidores, presentes nos tecidos envolventes ao embrião (MarcosFilho, 2005) que podem ser removidos pelas chuvas, sob condições naturais (Ross e Lembi, 2009).

Em algumas espécies, a exposição das sementes às baixas temperaturas, sob condições úmidas, estimula o crescimento de embriões rudimentares ou fisiologicamente imaturos (Geard et al., 2007; Ross e Lembi, 2009). Em sementes de erva-de-touro (Tridax procumbens L.) (Guimarães et al., 2000) e em alecrim-do-campo (Baccharis dracunculifolia) (Gomes e Fernandes, 2002), a temperatura afetou a dinâmica do processo de germinação.

A combinação de condições ambientais favoráveis para a germinação pode alterar o balanço hormonal e induzir a germinação. As giberelinas destacam-se por apresentar eficácia para promover superação da dormência em sementes (Taiz e Zeiger, 2004). O ácido giberélico é essencial para o processo germinativo, e em algumas espécies substitui o efeito da luz na germinação (Bradford, 2004).

O carrapicho-de-carneiro (Acanthospermum hispidum DC. - Asteraceae) se destaca por ser uma espécie indicadora de impacto ambiental, sendo sinalizadora de deficiência de cálcio no solo (Oliveira et al., 2004). Em áreas cultivadas, compete com as culturas reduzindo a produtividade. Possui ciclo anual, com caule ereto e folhas densamente pubescentes, chegando a atingir até $1 \mathrm{~m}$ de altura.

Os diásporos de $A$. hispidum são constituídos por aquênios triangulares, compridos, recobertos por cerdas irregulares, formados por brácteas involucrais dotadas de dois rostros distais divergentes, um reto e outro uncinado, que envolvem as sementes (Groth et al., 1980). Esses diásporos se mantêm no banco de sementes do solo por períodos entre 7 e 10 anos (Voll et al., 1997; Voll et al., 2001; Voll et al., 2003a).

Foram encontradas poucas informações sobre o processo reprodutivo de $A$. hispidum, mas não foram observados estudos relacionados à maturação e à dormência que auxiliem na compreensão de sua propagação. Desse modo, objetivou-se caracterizar, acompanhar e descrever o processo de maturação dos diásporos de carrapichode-carneiro (Acanthospermum hispidum DC.) e avaliar a natureza da sua dormência.

\section{Material e Métodos}

Para a realização do presente trabalho, foram conduzidos dois experimentos, utilizando diásporos de Acanthospermum hispidum obtidos de plantas de uma população espontânea, ocorrente na área experimental da Universidade Federal do Recôncavo da Bahia - UFRB, em Cruz das Almas, Bahia, Brasil.

Experimento 1 - Quando as plantas iniciaram o florescimento, em setembro de 2009, foi feita a marcação a cada sete dias, de capítulos que apresentavam flores femininas em antese, em plantas tomadas ao acaso, até o início da senescência das plantas e dispersão dos diásporos. O delineamento experimental foi inteiramente casualizado, totalizando cinco estádios de maturação, relacionados ao tempo após o início da antese floral (7, 14, 21, 28 e 35 dias). Após 35 dias do início do acompanhamento da maturação, plantas inteiras foram colhidas e levadas ao Laboratório de Análise de Sementes da UFRB, sendo então feita a separação dos diásporos de cada estádio, os quais foram identificados nas plantas, por meio de fitas coloridas, tendo sido utilizada uma cor a cada período.

Foi avaliado o comprimento, a largura e a espessura, utilizando uma amostra de 20 diásporos, em cada estádio de maturação, com o auxílio de um paquímetro, com medidas médias expressas em milímetros. A massa fresca de 100 diásporos foi determinada em oito repetições de 25 , utilizando metodologia adaptada de (Brasil, 2009).

Para a determinação do teor de água (\%), utilizaram-se 
quatro repetições de 25 diásporos pelo método da estufa a $105 \pm 3{ }^{\circ} \mathrm{C}$ por $24 \mathrm{~h}$, utilizando metodologia adaptada de Brasil (2009), com pesagem em balança analítica com precisão de $0,0001 \mathrm{~g}$, sendo o resultado expresso em porcentagem. A massa de matéria seca de 25 diásporos, também foi avaliada, sendo expressa em gramas.

Fez-se a avaliação da qualidade fisiológica das sementes constituintes dos diásporos, pelo teste de emergência de plântulas e pelo índice de velocidade de emergência (IVE). Foram utilizadas quatro repetições de 25 diásporos, totalizando 100 diásporos de cada estádio $(7,14,21,28$ e 35 dias), semeadas entre areia, em caixas de plástico tipo "gerbox", contendo $350 \mathrm{~g}$ de areia lavada e umedecidas com $45,0 \mathrm{~mL}$ de água, a qual representava $100 \%$ da capacidade de retenção de água do substrato, mantidas em câmara de germinação tipo BOD à temperatura de $25^{\circ} \mathrm{C}$ sob 16 horas de luz. A avaliação foi diária até sua estabilização, contandose como emergidas as plântulas em que a parte aérea se apresentava acima do substrato. $\mathrm{O}$ índice de velocidade de emergência (IVE) foi calculado conforme (Maguire, 1962).

Aos 210 dias, o experimento foi finalizado, avaliandose o número de diásporos em que suas sementes não germinaram, mas que continha sementes dormentes. Determinou-se também, o número de diásporos mortos, pela pressão com uma pinça, considerando-se mortos aqueles que não mantiveram sua estrutura íntegra.

Nos diásporos que resistiram à pressão, fez-se a extração manual dos embriões com o auxílio de uma lâmina cortante, para a realização de teste de tetrazólio, utilizando metodologia adaptada de (Brasil, 2009). Os embriões extraídos foram mantidos imersos em água até o início da coloração. A reação de coloração foi em uma solução de 2 , 3,5 trifenilcloreto de tetrazólio à $0,25 \%$, na ausência de luz, por duas horas a $30{ }^{\circ} \mathrm{C}$. Os diásporos em que os embriões ficaram rosados ou avermelhados foram considerados vivos, mas como não germinaram foram contados como dormentes.

Os diásporos sem sementes em seu interior foram considerados inviáveis, juntamente com aqueles cujos tecidos dos embriões apresentavam-se deteriorados ou que não se coraram, sendo incluídos na contagem de diásporos mortos. Os resultados dos diásporos dormentes e mortos foram expressos em porcentagem.

Experimento 2 - Esse experimento foi conduzido em julho de 2010 com a finalidade de determinar a natureza da dormência dos diásporos. Foram utilizados diásporos colhidos nas mesmas plantas, armazenados em embalagens semipermeáveis por 10 meses, sob condições ambientais de laboratório.
Para a determinação da natureza da dormência, diásporos foram submetidos aos tratamentos: escarificação manual com lixa número 100 na região distal; lavagem em água corrente por 24 horas; estratificação entre areia úmida, a $10{ }^{\circ} \mathrm{C}$ por sete dias; imersão em solução de ácido giberélico $\left(\mathrm{GA}_{3}\right)$ a $4000 \mathrm{mg} \mathrm{L}^{-1}$ por 24 horas; e o tratamento testemunha, constituído por diásporos intactos.

Os diásporos tratados foram colocados para germinar em câmara de germinação tipo BOD a $25^{\circ} \mathrm{C}$, sob fotoperíodo de 16 horas de luz. Os tratamentos foram constituídos por quatro repetições de 100 diásporos, no delineamento experimental inteiramente casualizado, em caixa de plástico contendo areia lavada, umedecida até a máxima capacidade de retenção de água, com um volume de água equivalente à $13 \%$ da massa da areia. Foram consideradas emergidas as sementes que apresentaram a parte aérea das plântulas acima do substrato. Determinou-se a porcentagem de emergência e o índice de velocidade de emergência de plântulas (IVE) (Maguire, 1962).

Os diásporos em que as sementes não germinaram foram submetidos ao teste de corte (Brasil, 2009) sendo considerados dormentes aqueles em que os embriões tinham seus tecidos íntegros e de coloração uniformemente clara; já aqueles que não continham sementes, ou que exibiam tecidos das sementes flácidos ou necrosados, de coloração escura, foram considerados como mortos.

Análise Estatística - Os dados das séries temporais do Experimento 1 foram transformados em $\operatorname{arcsen} \sqrt{ }(\mathrm{x} / 100)$ e submetidos à análise de regressão e ao teste $\mathrm{F}$ a $5 \%$ e a $1 \%$ de probabilidade. Ajustaram-se equações representativas dos modelos biológicos (Santana e Ranal, 2004), com auxílio do programa computacional Table Curve Pakage (Jandel Scientific, 1991). Quando não foi possível fazer o ajuste de equações representativas, os resultados médios foram apresentados em histogramas, acompanhados dos respectivos desvios padrões.

Os resultados do Experimento 2 foram transformados em $\operatorname{arcsen} \sqrt{ }(\mathrm{x} / 100)$, sendo testados quanto à independência da variância e à normalidade dos dados, pelos testes de Hartley e Kolmogorov-Smirnov, respectivamente. Posteriormente, foram submetidos ao teste $\mathrm{F}$ na análise de variância sendo feita a comparação das médias pelo teste de Tukey a 5\% de probabilidade (Santana e Ranal, 2004).

\section{Resultados e Discussão}

As dimensões dos diásporos apresentaram distinções entre si, havendo aumento progressivo do comprimento ao longo da maturação (Figura 1a), enquanto a largura 
teve incrementos até os 21 dias, reduzindo posteriormente (Figura 1b). Já a espessura apresentou menores variações, com incremento somente até os 14 dias e suave regressão das medidas aos 35 dias da antese (Figura 1c). Os incrementos de medidas indicam o investimento da planta em suas estruturas de dispersão, as quais não apresentam grandes amplitudes em razão dos estádios iniciais já partirem do invólucro-gamófilo que apresenta certo desenvolvimento, desse modo, as medidas dos diásporos tendem a não apresentar grandes incrementos. Mas as reduções nas medidas da largura e da espessura representam o resultado da desidratação das unidades de dispersão, verificado visualmente a partir dos 21 dias e na massa de 100 diásporos (Figura 1d).
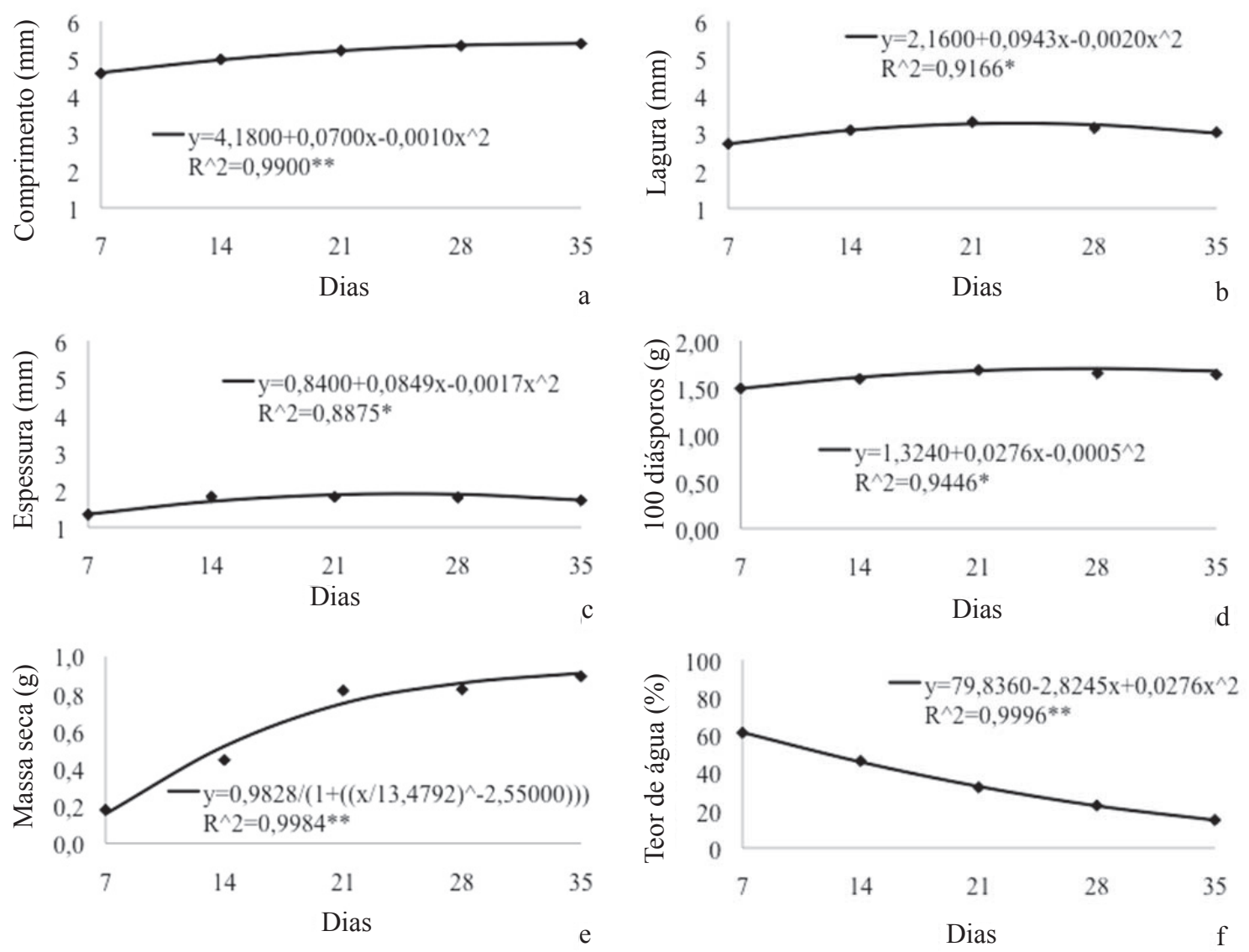

Figura 1. Alterações nas dimensões e em atributos físicos nos diásporos de Acanthospermum hispidum DC. (Asteraceae) ao longo da maturação, avaliados durante 35 dias após a antese floral. a. Comprimento médio dos diásporos; b. Largura média dos diásporos; c. Espessura média dos diásporos; d. Massa fresca média de 100 diásporos; e. Massa seca média de 100 diásporos; f. Teor de água porcentual dos diásporos.

*,** Resultados significativos a $5 \%$ e a $1 \%$ de probabilidade, respectivamente, pelo teste $\mathrm{F}$.

O maior comprimento dos diásporos ocorreu aos 35 dias da antese (Figura 1a) e coincidiu com o início da dispersão natural. A maior largura foi atingida aos 24 dias e a maior espessura aos 25 dias sendo obtidas pela determinação do ponto de máximo, nas equações ajustadas. As variações ocorridas nas dimensões ao longo dos estádios foram significativas pelo teste $\mathrm{F}$ para o comprimento $(\mathrm{p}<0,01)$ e para a largura e espessura $(\mathrm{p}<0,05)$, indicando que ocorrem alterações relevantes nas dimensões dos diásporos ao longo da maturação.

A massa da matéria fresca de 100 diásporos aumentou até os 21 dias (Figura 1d). Em calêndula as unidades de dispersão são muito mais leves que os diásporos de $A$. hispidum, entre 5,0 e $11,0 \mathrm{~g}$ a cada mil sementes (Silveira et al., 2002). A formação de sementes mais leves usualmente está associada a dispersão anemófila, 
conforme observaram Duarte et al. (2009), porém os apêndices uncinados dos diásporos de $A$. hispidum indicam características de dispersão epizoocórica, conforme descreveu (Nathan, 2007).

$\mathrm{O}$ incremento da massa seca dos diásporos não foi acompanhado pelo incremento na massa fresca, demonstrando que as estruturas dos diásporos sofrem pouca variação ao longo da maturação. O maior acúmulo de massa seca ocorreu aos 35 dias atingindo 0,9 g. A partir dos 21 dias, houve tendência de estabilização nos incrementos (Figura 1e), indicando que a maturidade de massa é atingida após 21 dias da maturação. Nakagawa et al. (2007) verificaram o aumento de massa seca de sementes de mucuna-preta no final da maturação, o que também ocorreu em A. hispidum.

As pequenas variações de massa seca dos diásporos verificadas no presente estudo podem estar relacionadas à proporção relativa que as sementes representam nos frutos, conforme foi discutido por Fenner (1983), que demonstrou que a massa dos embriões em sementes de 24 espécies de Asteraceae, nos primeiros 21 dias, representava menores incrementos relativos em sementes mais pesadas, nas quais os embriões são proporcionalmente menores e os tegumentos são mais desenvolvidos. Tais observações corroboram com as observações feitas no presente estudo.

À medida que a maturação avançou, o teor de água dos diásporos reduziu, partindo de $61,2 \%$ após uma semana da antese, chegando a $14,8 \%$ aos 35 dias (Figura 1f). Aos 21 dias o teor de água foi de $32,2 \%$ e já haviam iniciado a estabilização do acúmulo de massa seca, indicando proximidade da maturidade fisiológica. Guimarães et al. (1998) verificaram resultados semelhantes para sementes de Zinia elegans (Asteraceae) em um período entre 20 e 50 dias após a antese floral, porém, no final da avaliação quando ocorreu a maturidade fisiológica, as sementes de Z. elegans apresentavam teor de água de $20 \%$.

A emergência de plântulas foi observada em diásporos que apresentaram mais de 14 dias de idade, atingindo apenas 7,0\%. Aos 21 dias após antese, foi de 45,0\%, voltando a exibir menores médias nos estádios posteriores (Figura 2a), devido à instalação da dormência a partir dos 28 dias (Figura 3a). Os diásporos aos 14 dias apresentaram menor capacidade de emergência (Figura 2a), atribuída em parte à imaturidade fisiológica das sementes, pois, esses diásporos exibiram 67,0\% de dormência (Figura 3a). Dias e Nascimento (2009) relataram que quando as sementes apresentam capacidade de germinação cedo, geralmente ocorre dormência quando as sementes atingem certo grau de desenvolvimento, corroborando os resultados anteriormente apresentados.
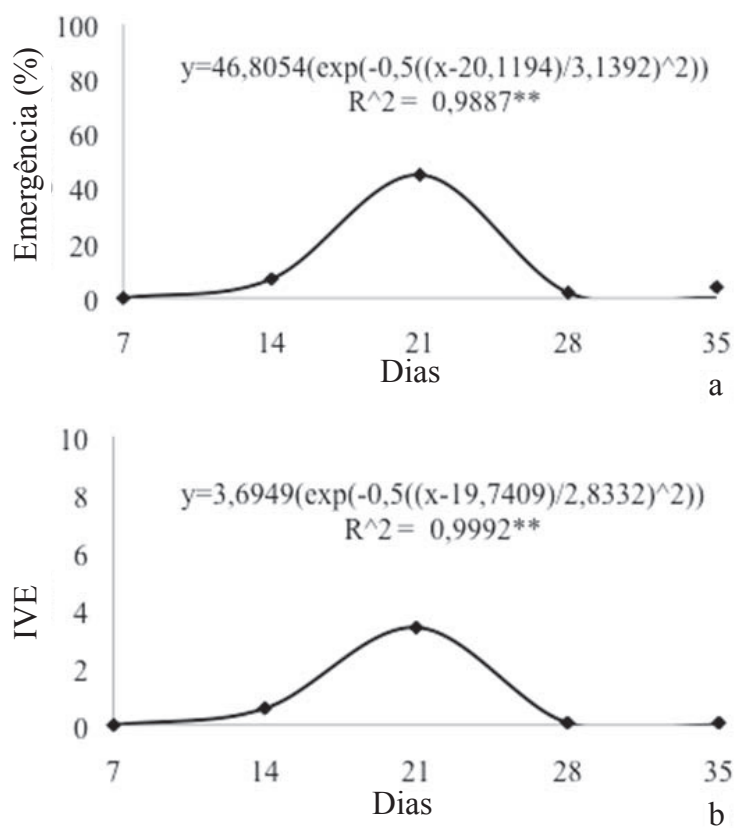

Figura 2. Emergência de plântulas e índice de velocidade de emergência (IVE) em sementes de Acanthospermum hispidum DC. (Asteraceae), obtidas de diásporos com diferentes graus de maturação, avaliados ao longo de 35 dias após a antese floral. a. Porcentagem média de emergência; $b$. IVE médio.

** Resultados significativos a 1\% de probabilidade, pelo teste F.

O índice de velocidade de emergência (IVE) apresentou comportamento semelhante ao da emergência de plântulas (Figuras 2a e 2b), representando o aumento do vigor em diásporos com 21 dias de idade.

As maiores porcentagens de sementes dormentes foram verificadas em diásporos com 28 e 35 dias após a antese, com médias de $80,0 \%$ e $77,0 \%$, respectivamente (Figura 3a). Ao mesmo tempo, as menores taxas de mortalidade foram verificadas para os mesmos períodos, atingindo $12,0 \%$ e 17,0\%, respectivamente (Figura 3b). Creditam-se esses resultados à melhor formação das estruturas dos diásporos e sementes nos últimos estádios de maturação, nos quais, a dormência dos diásporos é o principal fator de redução da emergência. Lazaroto et al. (2008), revisando aspectos da biologia de buva (Conyza spp), relataram que as sementes completaram a maturação em 21 dias, mas quando as sementes já estavam totalmente maduras não 
apresentaram dormência. Ooi (2007) relatou que apesar de serem conhecidas espécies de Asteraceae em que as sementes não possuem dormência, em outras espécies, as sementes podem apresentá-la, conforme verificado em sementes de A. hispidum.
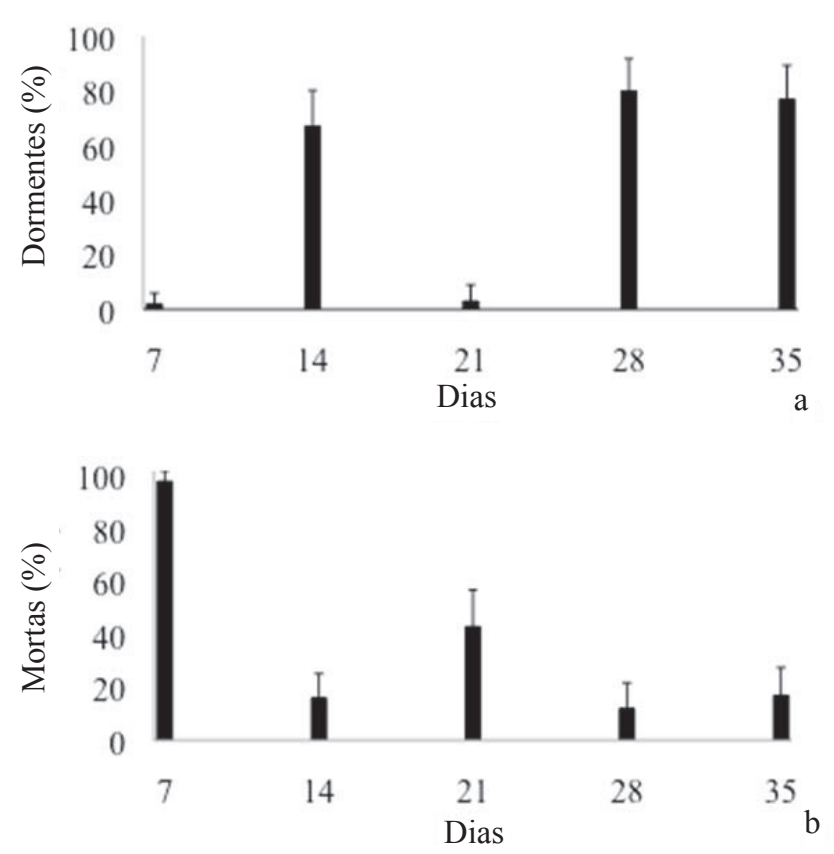

Figura 3. Dormência e mortalidade em sementes e diásporos de Acanthospermum hispidum DC. (Asteraceae) ao longo da maturação, avaliados durante 35 dias após a antese floral. a. Porcentagem média de sementes dormentes; b. Porcentagem média de sementes e diásporos mortos.

Verificou-se alta mortalidade $(98,0 \%)$ em diásporos aos 7 dias após a antese (Figura 3b), devendo-se à estrutura pouco desenvolvida das sementes. Aos 21 dias a porcentagem de dormência das sementes foi menor $(3,0 \%)$, mas a porcentagem de sementes mortas foi maior $(43,0 \%)$. Parte da mortalidade é creditada à inclusão de diásporos vazios, que não formaram sementes. Uma vez que diásporos que continham sementes e aqueles em que as sementes não se desenvolveram normalmente, foram utilizados indistintamente no presente estudo, por não apresentarem características externas que permitissem sua identificação.

Considerando o conjunto das variáveis físicofisiológicas avaliadas nos diásporos de A. hispidum, verificou-se que a maturidade fisiológica foi alcançada a partir dos 21 dias da antese floral, quando ocorreu máximo acúmulo de massa seca, máxima emergência e vigor (IVE), corroborando com critérios descritos por (Peske et al., 2006). O momento de máximo conteúdo de matéria seca é considerado o melhor e mais seguro indicativo de que as sementes atingiram maturidade fisiológica (Dias e Nascimento, 2009). Silveira et al. (2002) verificaram que maturidade fisiológica de sementes de calêndula (Calendula officinalis L.), uma Asteraceae herbácea, ocorreu entre 28 e 32 dias após a antese floral, em período maior que o avaliado no presente estudo.

A avaliação da natureza da dormência demonstrou que a escarificação com lixa não foi eficaz para promover a emergência de plântulas, além de aumentar a mortalidade $(43,8 \%)$ dos diásporos (Tabela 1$)$, devido à danos causados nos cotilédones, já que o tegumento é fino. A ocorrência de danos mecânicos causando morte em sementes de plantas daninhas está em consonância com o relato de Ross e Lembi (2009), que atribuíram o aumento de mortalidade em sementes escarificadas à ação de microrganismos. Além dos danos causados ao embrião, os resultados de germinação e dormência em diásporos e sementes de $A$. hispidum evidenciam que a natureza da dormência não é tegumentar, pois, não se verificou efeitos significativos para a escarificação em relação à testemunha, constituída por diásporos intactos.

A maioria dos tratamentos pré-germinativos para a superação da dormência foram semelhantes à testemunha, excetuando-se o tratamento com $\mathrm{GA}_{3}$, que promoveu aumento da emergência $(\mathrm{p}<0,05)$ de $A$. hispidum, apresentando a maior média (46,5\%) (Tabela 1). A aplicação de $\mathrm{GA}_{3}$ em sementes de macela (Egletes viscosa (L.) Less.) também aumentou a porcentagem de germinação e a velocidade de germinação (Bezerra et al., 2006). Os efeitos das giberelinas na indução do consumo das reservas são conhecidos, promovendo superação da dormência fisiológica em sementes maduras (Bradford, 2004; MarcosFilho, 2005). Nas Asteraceae, que apresentam sementes com dormência, essa é de natureza fisiológica (Ooi, 2007), como pode ocorrer em girassol (Helianthus annuus L.), que apresenta embrião fisiologicamente dormente (MarcosFilho, 2005), sendo essa a natureza da dormência também verificada em diásporos de $A$. hispidum.

A emergência de plântulas foi semelhante entre diásporos recém-colhidos aos 21 dias no estudo de maturação e aqueles armazenados por 10 meses e tratados com $\mathrm{GA}_{3}$, indicando que o período de armazenamento não reduziu a capacidade de emergência.

As porcentagens de emergência de plântulas foram menores que $50 \%$ no experimento de maturação e no experimento de determinação da natureza da dormência, 
podendo refletir possíveis problemas na taxa de fecundação e formação de sementes. Voll et al. (2003b) verificaram germinação de A. hispidum de 6,9\%. A baixa germinação e emergência nessa espécie podem se constituir em um problema, quando ela está presente no banco de sementes do solo em áreas agrícolas, tendo sido verificado por Voll et al. (2001) 472 diásporos $\mathrm{m}^{-2}$ em uma área agrícola que se mantiveram viáveis no banco de sementes do solo por 7 a 10 anos, além disso, Blanco e Blanco (1991) observaram até 23 plantas a cada $1,5 \mathrm{~m}^{2}$.

Tabela 1. Emergência de plântulas, índice de velocidade de emergência (IVE), dormência e mortalidade de diásporos de Acanthospermum hispidum DC. (Asteraceae), submetidos a diferentes tratamentos para superação de dormência.

\begin{tabular}{ccccc}
\hline Tratamentos & Emergência (\%) & IVE & Dormentes (\%) & Mortos (\%) \\
\hline Escarificação com lixa & $23,2 \mathrm{~b}$ & $6,6 \mathrm{bc}$ & $33,0 \mathrm{~b}$ & $43,8 \mathrm{a}$ \\
Água corrente por $24 \mathrm{~h}$ & $19,8 \mathrm{~b}$ & $4,7 \mathrm{c}$ & $57,0 \mathrm{a}$ & $23,2 \mathrm{bc}$ \\
Estratificação a $10{ }^{\circ} \mathrm{C} / 7$ dias & $24,2 \mathrm{~b}$ & $7,2 \mathrm{~b}$ & $59,0 \mathrm{a}$ & $16,8 \mathrm{c}$ \\
$\mathrm{GA}_{3}$ a $4000 \mathrm{mg} \mathrm{L}^{-1}$ & $46,5 \mathrm{a}$ & $12,4 \mathrm{a}$ & $30,5 \mathrm{~b}$ & $23,0 \mathrm{bc}$ \\
\hline Testemunha & $24,8 \mathrm{~b}$ & $5,6 \mathrm{bc}$ & $51,5 \mathrm{a}$ & $23,5 \mathrm{bc}$ \\
\hline
\end{tabular}

* Médias seguidas por letras distintas, nas colunas, diferem entre, 1 e 5\% de probabilidade pelo teste de Tukey.

Outro aspecto a ser considerado, para explicar a baixa emergência, é a possibilidade de que os diásporos de $A$. hispidum formados em diferentes posições na planta possam apresentar diferentes capacidades de germinação e dormência, conforme discutiram Tomaz et al. (2004) para sementes de cordão-de-frade (Leonotis nepetaefolia), o que poderá ser melhor explorada em novos estudos.

O IVE das sementes/diásporos submetidos ao $\mathrm{GA}_{3}$ $(12,4)$ também foi maior (Tabela 1), demonstrando o efeito do regulador vegetal na aceleração da germinação. Tais resultados concordam com relatos de Bezerra et al. (2006) para macela (E. viscosa). Contudo, a baixa emergência de plântula e a desuniformidade deste processo em $A$. hispidum são as causas dos menores IVEs nos demais tratamentos pré-germinativos (escarificação, água corrente, estratificação e testemunha), não representando redução no vigor, mas constituindo-se em um problema para o controle das plantas daninhas, conforme expuseram Marcos-Filho (2005) e Ross e Lembi (2009), pois, a baixa uniformidade de emergência pode resultar em desuniformidade no comportamento fenológico da planta daninha, e consequentemente no aumento do potencial de interferência nas culturas.

Em diásporos submetidos à estratificação a $10{ }^{\circ} \mathrm{C}$ por sete dias, houve concentração da emergência nas primeiras duas semanas de avaliação, como resultado da hidratação inicial, feita durante a estratificação, não representando incrementos no vigor expresso pelo IVE, visto que, a emergência, a dormência e a mortalidade não foram significativamente afetadas pelo tratamento. Mas, considerou-se que esses resultados podem decorrer do período curto (uma semana) de exposição à estratificação, uma vez que algumas espécies ficam nessa condição durante todo o período de inverno (de duas semanas a oito meses) (Carvalho et al., 2005; Ross e Lembi, 2009). A baixa temperatura pode ser utilizada para a superação da dormência, como ocorre em sementes de carqueja (Baccharis trimera (Less.) DC.) (Carvalho et al., 2005), pois nesses casos pode ocorrer a produção de enzimas hidrolíticas que auxiliam na produção de giberelinas e/ou redução de inibidores, ao mesmo tempo, a estratificação pode favorecer o desenvolvimento de microrganismos em sementes não dormentes (Marcos-Filho, 2005). Dessa forma, recomenda-se a exposição dos diásporos de $A$. hispidum a períodos de estratificação maiores que sete dias, para uma melhor avaliação desse tratamento sobre a emergência dos diásporos.

A lavagem dos diásporos em água corrente por $24 \mathrm{~h}$ resultou em IVE menor (Tabela 1), indicando certo efeito inibidor desse tratamento sobre a emergência $(19,8 \%)$, pois, emergiram mais desuniformemente, produzindo IVE médio de 4,7. Marcos-Filho (2005) relatou que a lavagem das sementes em água corrente pode levar a perda da compartimentalização celular e a liberação de solutos devido à rápida entrada de água, levando a redução da germinação de sementes não dormentes. Tais aspectos, necessitam serem melhor explorados em futuros trabalhos com diásporos de $A$. hispidum, a fim de elucidar as causas da redução de vigor.

As maiores porcentagens de diásporos dormentes ocorreram nos tratamentos testemunha, água corrente e de estratificação (Tabela 1), indicando sua ineficácia 
para estimular o processo germinativo em A. hispidum e demonstrando que a natureza da dormência não está relacionada a esses tratamentos.

\section{Conclusões}

A maturidade fisiológica em diásporos de A. hispidum é indicada pela seca dos ganchos (rostros), aos 21 dias da antese floral, após esse período, a dormência se instala, sendo dispersos diásporos dormentes.

A dormência dos diásporos de $A$. hispidum é de natureza fisiológica e pode ser superada pela imersão em solução de $\mathrm{GA}_{3}$.

\section{Referências}

BEZERRA, A.M.E.; MEDEIROS FILHO, S.; ALCÂNTARA BRUNO, R.L.; MOMENTE, V.G. Efeito da pré-embebição e aplicação de ácido giberélico na germinação de sementes de macela. Revista Brasileira de Sementes, v.18, n.3, p.185-190, 2006. http://www.abrates.org.br/revista/ artigos/2006/v28n3/artigo26.pdf

BLANCO, H.G.; BLANCO, F.M.G. Efeito do manejo do solo na emergência de plantas daninhas anuais. Pesquisa Agropecuária Brasileira, v.26, n.2, p.215-220, 1991. http://webnotes.sct.embrapa.br/ pdf/pab1991/fevereiro/pab09_fev_91.pdf

BRADFORD, K.J. Seed production and quality. Davis: University of California. 2004. 134p.

BRASIL. Ministério da Agricultura, Pecuária e Abastecimento. Regras para análise de sementes. Ministério da Agricultura, Pecuária e Abastecimento. Secretaria de Defesa Agropecuária. Brasília: MAPA/ACS, 2009. 395p. http://www.agricultura.gov.br/arq_editor/file/Laborat $\% \mathrm{C} 3 \% \mathrm{~B} 3$ rio/ Sementes/Regras\%20para\%20Analise\%20de\%20Sementes.pdf

CARVALHO, R.I.; GIUBLIN, L.M.; RIPKA, M.; WACHOWICZ, C.M.; NOLASCO, M.A.; SCHEFFER, M.C.; RADOMSKI, M.I. Préesfriamento e temperatura para germinação de sementes de carqueja. Scientia Agraria, v.6, n.1-2, p.79-84, 2005. http://ojs.c3sl.ufpr.br/ojs2/ index.php/agraria/article/view/4598/3557

DIAS, D.C.F.S.; NASCIMENTO, W.M. Desenvolvimento, maturação e colheita de sementes de hortaliças. In: NASCIMENTO, W.M. (Ed.). Tecnologia de sementes de hortaliças. Brasília: Embrapa Hortaliças, 2009. p.11-74.

DUARTE, E.F.; CARNEIRO, I.F.; REZENDE, M.H. Morfologia de frutos e sementes e desenvolvimento pós-seminal de Dyckia goehringii Gross \& Rauh (Bromeliaceae). Revista de Biologia Neotropical, v.6, n.1, p.1-12, 2009. http://www.revistas.ufg.br/index.php/RBN/article/view/12626

FENNER, M. Relationships between seed weight, ash content and seedling growth in twenty-four species of Compositae. New
Phytologist, v.95, n.4, p.697-706, 1983. http://onlinelibrary.wiley.com/ doi/10.1111/j.1469-8137.1983.tb03533.x/pdf

GEARD, A.; SPURR, C.J.; BROWN. Embryo development and time of cutting in cool temperature carrot seed crops. In: ADKINS, S.W.; ASHMORE, S.E.; NAVIE, S.C. (Eds.). Seeds: biology, development and ecology. Oxfordshire: CABI, 2007, p.120-129.

GOMES, V.; FERNANDES, G.W. Germinação de aquênios de Baccharis dracunculifolia DC. (Asteraceae). Acta Botânica Brasilica, v.16, n.4, p.421-427, 2002. http://www.scielo.br/scielo. php?script=sci_arttext\&pid=S0102-33062002000400005\&lng=pt\&n $\mathrm{rm}=\mathrm{iso} \& \mathrm{t} \operatorname{lng}=\mathrm{pt}$

GUIMARÃES, T.G.; OLIVEIRA, D.A.; MANTOVANI-ALVARENGA, E.; GROSSI, J.A.S. Maturação fisiológica de sementes de zínia (Zinia elegans Jacq.). Revista Brasileira de Sementes, v.20, n.1, p.7-11, 1998. http://www.abrates.org.br/revista/artigos/1998/v20n1/artigo02.pdf

GUIMARÃES, S.C.; SOUZA, I.F.; PINHO, E.V.R.V. Efeito de temperaturas sobre a germinação de sementes de erva-de-touro (Tridax procumbens). Planta Daninha, v.18, n.3, p.457-464, 2000. http://www.scielo.br/scielo.php?script=sci_arttext\&pid=S0100$83582000000300010 \& \operatorname{lng}=$ pt\&nrm=iso\&tlng=pt

GROTH, D.; BOARETTO, M.R.; SILVA, R.N. Morfologia de sementes, frutos e plantas invasoras em algumas culturas. Revista Brasileira de Sementes, v.2, n.2, p.67-98, 1980. http://www.abrates.org.br/revista/ artigos/1980/v2n2/artigo07.pdf

JANDEL SCIENTIFIC. Table curve: curve fitting software. Corte Madera: Jandel Scientific. 1991, 280p.

LAZAROTO, C.A.; FLECK, N.F.; VIDAL, R.A. Biologia e ecofisiologia de buva (Conyza bonariensis e Conyza canadensis). Ciência Rural, v.38, n.3, p.852-860, 2008. http://www.scielo.br/scielo.php?script=sci arttext\&pid $=$ S0103-84782008000300045\&lng=en\&nrm=iso\&tlng=pt

MAGUIRE, J.D. Speed of germination-aid in selection and evaluation for seedling emergence and vigor. Crop Science, v.2, n.2, p.176-177, 1962.

MARCOS-FILHO, J. Fisiologia de sementes de plantas cultivadas. Piracicaba: FEALQ, 2005. 495p.

MARTINS, O.; MARTINS, C.C.; CARBONARI, C.A.; TERRA, M.A. Qualidade fisiológica de sementes de leiteiro (Peschiera fuchsiaefolia) em função do estádio de maturação dos frutos. Planta Daninha, v.22, n.4, p.539-544, 2004. http://www.scielo.br/scielo.php?script=sci arttext\&pid $=$ S0100-83582004000400007\&lng=pt\&nrm=iso\&tlng=pt

NAKAGAWA, J.; ZUCARELI, C.; CAVARIANI, C.; GASPAROLIVEIRA, C. Maturação de sementes de mucuna-preta. Bioscience Journal, v.23, n.1, p.41-47, 2007. http://www.seer.ufu.br/index.php/ biosciencejournal/article/view/6381/4119

NATHAN, R. Total dispersal kernels and the evaluation of diversity and similarity in complex dispersal systems. In: DENNIS, A.J.; SCHUPP, 
E.W.; GREEN, R.J; WESTCOTT, D.A. Seed dispersal: theory and its application in a changing world. Oxfordshire: CABI, 2007. p.252-276.

OLIVEIRA, F.N.S.; FREIRE, F.C.O.; AQUINO, A.R.L. Bioindicadores de impacto ambiental em sistemas agrícolas orgânicos. Fortaleza, Embrapa Agroindústria Tropical, 2004, 24p. (Documentos, 93).

OOI, M.K.J. Dormancy classification and potential dormancy-breaking cues for shrub species from fire-prone South-easten Australia. In: ADKINS, S.W.; ASHMORE, S.E.; NAVIE, S.C. (Eds.). Seeds: biology, development and ecology. Oxfordshire: CABI, 2007, p.205-216.

PESKE, S.T.; LUCCA FILHO, O.A.; BARROS, A.C.S.A. Sementes: fundamentos científicos e tecnológicos. Pelotas: Editora e Gráfica Universitária, 2006. 472p.

ROSS, M.A.; LEMBI, C.A. Applied weed science. Columbus: Pearson Prentice Hall: New Jersey, 2009. 561p.

SANTANA, D.G.; RANAL, M.A. Análise da germinação: um enfoque estatístico. Brasília: Editora da Universidade de Brasília, 2004. 248p.

SILVEIRA, M.A.M.; VILLELA, F.A.; TILLMANN, M.A.A. Maturação fisiológica de sementes de calendula (Calendula officinalis L.). Revista Brasileira de Sementes, v.24, n.2, p.31-37, 2002. http://www.scielo.br/ scielo.php?script $=$ sci_arttext\&pid=S0101-31222002000100006\&lng=e $\mathrm{n} \& \mathrm{nrm}=\mathrm{iso} \& \mathrm{tlng}=\mathrm{pt}$

TAIZ, L.; ZEIGER, E. Fisiologia vegetal. Porto Alegre: Artmed, 2004. 719p.

TOMAZ, M.A.; ARAÚJO, E.F.; FERREIRA, F.A.; SAGRILO, E. Germinação de sementes de Leonotis nepetaefolia, em função do estádio de maturação e da posição do glomérulo na planta. Planta Daninha, v.22, n.3, p.359-364, 2004. http://www.scielo.br/scielo.php?script=sci_
arttext\&pid=S0100-83582004000300005\&lng=pt\&nrm=iso\&tlng=pt

VIVIAN, R.; SILVA, A.A.; GIMENES JUNIOR, M.; FAGAN, E.B.; RUIZ, S.T.; LABONIA, V. Dormência em sementes de plantas daninhas como mecanismo de sobrevivência - breve revisão. Planta Daninha, v.26, n.3, p.695-706, 2008. http://www.scielo.br/scielo.php?script=sci arttext\&pid $=$ S0100-83582008000300026\&lng $=$ pt\&nrm $=$ iso\&tlng $=p t$

VOLL, E.; GAZZIERO, D.L.P.; KARAM, D. Dinâmica de populações de carrapicho-de-carneiro (Acanthospermum hispidum DC.) sob manejos de solo e de herbicidas. Pesquisa Agropecuária Brasileira, v.32, n.9, p.18, 1997. http://webnotes.sct.embrapa.br/pab/pab.nsf/FrAnual

VOLL, E.; TORRES, E.; BRIGHENTI, A.M.; GAZZIERO, D.L.P. Dinâmica do banco de sementes de plantas daninhas sob diferentes sistemas de manejo de solo. Planta Daninha, v.19, n.2, p.171-178, 2001. http://www.scielo.br/scielo.php?script=sci_arttext\&pid=S0100$83582001000200003 \& \operatorname{lng}=$ pt\&nrm $=$ iso $\&$ tlng $=$ pt

VOLL, E.; ADEGAS, F.S.; GAZZIERO, D.L.P.; BRIGHENTI, A.M.; OLIVEIRA, M.C.N. Amostragem do banco de sementes e flora emergente de plantas daninhas. Pesquisa Agropecuária Brasileira, v.38, n.2, p.211-218, 2003a. http://webnotes.sct.embrapa.br/pdf/pab2003/ fevereiro/211.pdf

VOLL. E.; BRIGHENTI, A.M.; GAZZIERO, D.L.P.; ADEGAS, F.S. Relações entre germinação de sementes de espécies de plantas daninhas e uso da condutividade elétrica. Planta Daninha, v.21, n.2, p.181-189, 2003b. http://www.scielo.br/scielo.php?script=sci_arttext\&pid=S0100$83582003000200003 \& \operatorname{lng}=$ pt\&nrm $=$ iso \& $\operatorname{lng}=$ pt 